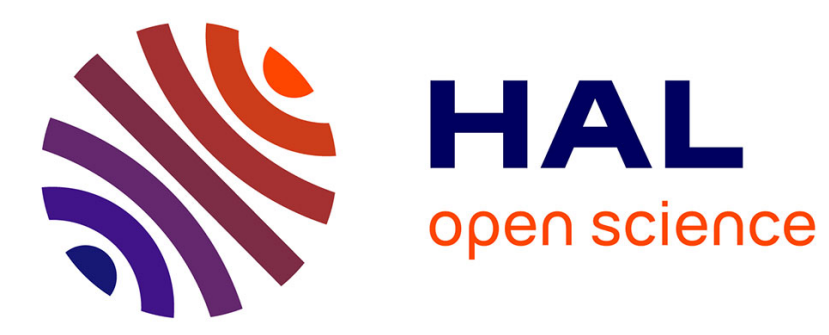

\title{
Growth Kinetics of Copper Films from Photoassisted CVD of Copperacetylacetonate
}

\author{
D. Tonneau, R. Pierrisnard, H. Dallaporta, W. Marine
}

\section{To cite this version:}

D. Tonneau, R. Pierrisnard, H. Dallaporta, W. Marine. Growth Kinetics of Copper Films from Photoassisted CVD of Copperacetylacetonate. Journal de Physique IV Proceedings, 1995, 05 (C5), pp.C5-629-C5-635. 10.1051/jphyscol:1995575 . jpa-00253937

\section{HAL Id: jpa-00253937 https://hal.science/jpa-00253937}

Submitted on 1 Jan 1995

HAL is a multi-disciplinary open access archive for the deposit and dissemination of scientific research documents, whether they are published or not. The documents may come from teaching and research institutions in France or abroad, or from public or private research centers.
L'archive ouverte pluridisciplinaire HAL, est destinée au dépôt et à la diffusion de documents scientifiques de niveau recherche, publiés ou non, émanant des établissements d'enseignement et de recherche français ou étrangers, des laboratoires publics ou privés. 


\title{
Growth Kinetics of Copper Films from Photoassisted CVD of Copperacetylacetonate
}

\author{
D. Tonneau, R. Pierrisnard, H. Dallaporta and W. Marine \\ Faculté des Sciences de Luminy, GPEC, Case 901, 13288 Marseille cedex 09, France
}

\begin{abstract}
Copper thin films have been deposited by thermal decomposition of copper acetylacetonateoxygen mixtures. Copper films of high quality as observed by Auger Electron Spectroscopy (AES) have been obtained at temperatures as low as $300^{\circ} \mathrm{C}$. Under UV illumination, this temperature threshold decreased down to $225^{\circ} \mathrm{C}$. The influence of substrate temperature and layer thickness on film roughness as observed by Atomic Force Microscopy is discussed. The kinetics of $\mathrm{Cu}(\mathrm{acac})_{2}$ decomposition has been investigated as a function of precursor partial pressure and substrate temperature in the range of 200 $350^{\circ} \mathrm{C}$, and the maximum deposition rate of $25 \AA / \mathrm{min}$ has been reached in the mass transport regime at a substrate temperature of $350^{\circ} \mathrm{C}$ and a precursor partial pressure of 0.04 Torr. The deposition rate could be substancially enhanced by UV photoassistance.
\end{abstract}

\section{INTRODUCTION}

Metallorganic Chemical Vapor Deposition is now widely investigated for IC metallization applications in the field of microelectronics. In fact, when the precursor molecules are compounds without direct metal-carbon chemical bonds, the metal deposits obtained by this technique are generally very pure. Furthermore, since the dative bond between the metal atom and the organic part of the precursor is very weak, the reaction occurs at low temperatures (usually lower than $300^{\circ} \mathrm{C}$ ) and the deposition rates are very high. More precisely a great amount of interest has been devoted to copper thin film processes due to its low resistivity, for IC metallization applications : packaging (Multilevel metallization- MLM) or on-chip metallization [1-4].

Among commonly marketted copper precursors, $\mathrm{Cu}(\mathrm{acac})_{2}$ has been widely used due to its high stability in ambient atmosphere at room temperature which allows to easily transfer the precursor from the storage container to the vessel fitted to the experimental set-up.

The purpose of the present work is to study the growth of copper from the decomposition of the gaseous precursor copper (II) acetylacetonate carried by oxygen. The deposit composition has been determined by in-situ Auger Electron Spectroscopy (AES) analysis and the film roughness has been observed as a function of experimental conditions by Atomic Force Microscopy (AFM) analysis. Deposition kinetics have been studied and finally the effect of UV photoassistance on the deposition rate has been proved.

\section{EXPERIMENTAL SET-UP}

The experimental set-up has been detailed in previous papers [5, 6]. Briefly a conventional low pressure cold-wall CVD reactor is linked to a Cylindric Mirror Auger (CMA) analyzer. Consequently the samples can be analyzed in-situ after transfer from the chemical chamber to the Auger analyzer. The reaction chamber is equipped with a quartz window allowing UV irradiation of the substrates during copper layer processing. The UV light is provided by an arc xenon lamp ; the emitted spectrum was filtered 
by a coloured filter allowing to cut the IR part of the spectrum, in order to avoid a non controlled extra substrate heating by the lamp.

The copper precursor is the metallorganic copper acetylacetonate, $\mathrm{Cu}(\mathrm{acac})_{2}$. It is kept in a vessel, the temperature of which can be fixed in the range of $25-140^{\circ} \mathrm{C}$, temperatures providing vapor pressures of $3.10^{-4}$ and $8.10^{-2}$ Torr respectively (Figure 1). The precursor is carried by oxygen and the total flux in the chemical chamber can be varied between 0.1 and $10 \mathrm{sccm}$ while the total pressure was fixed in the range of $10^{-2}-10^{-1}$ Torr. The sample is placed on a heated substrate holder allowing to operate at temperatures up to $400^{\circ} \mathrm{C}$. The reactor walls are heated to avoid precursor condensation during experiments.

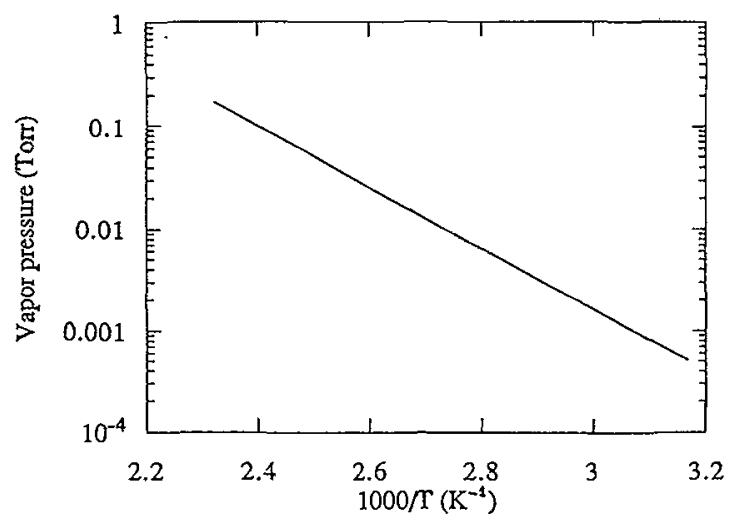

Figure 1: Dependence of the copper acetylacetonate $\mathrm{Cu}(\mathrm{acac})_{2}$ vapor pressure on the temperature.

The substrates are silicon substrates coated with a $1000 \AA$ thick thermal silicon dioxide layer. They are degreased in conventional solvents (trichlorethylen, aceton and ethanol) and finally rinsed in deionized water before introduction in the reaction chamber. Two samples were systematically placed simultaneously on the substrate holder, one of them being irradiated by the UV beam, in order to observe in each experimental condition the influence of the UV irradiation on the deposition kinetics and on the deposit morphology.

The deposit composition has been estimated by in-situ Auger analyses and the layer roughness and grain size have been evaluated by Atomic Force Microscopy (AFM) analyses. Finally the deposit thicknesses were measured by stylus profilometry.

\section{RESULTS}

It was observed that the copper acetylacetonate decomposition occurred only in presence of oxygen in the chemical chamber. If oxygen was replaced by helium, no deposition was observed. The copper acetylacetonate dilution $\mathrm{O}_{2} / \mathrm{Cu}(\mathrm{acac})_{2}$ is a very critical parameter and had to be chosen in the range 1.5-2 to lead to the formation of a copper film in the case of UV photoassisted reaction and 1.5-2.5 without photoassistance. In fact when this ratio was increased up to values higher than 2 during the deposition process, the film deposited became dark blue, characteristic colour of copper oxide, and the reaction stopped. The formation of copper oxide occurred only at the film surface and consequently this surface oxide could be desorbed by decreasing the partial pressure of oxygen in the chamber, and the deposition reaction of copper could restart.

The film contamination by carbon and oxygen has been analyzed from AES studies (Figure 2). Figure $2 \mathrm{a}$ shows a typical spectrum obtained with a film as processed. The process temperature was $375^{\circ} \mathrm{C}$, the total pressure $10^{-1} \mathrm{Torr}$, the gas flow $1 \mathrm{sccm}$ and the ratio $\mathrm{O}_{2} / \mathrm{Cu}(\mathrm{acac})_{2}=1.5$. The presence of carbon and oxygen is detected. However, after surface cleaning by argon ion gun $(\mathrm{U}=30 \mathrm{kV}, \mathrm{I}=5 \mu \mathrm{A})$, 
the contribution of contaminants decreases drastically (Figure 2b). The copper $\mathrm{M}_{23} \mathrm{VV}$ doublet at $60 \mathrm{eV}$ was resolved, indicating the presence of metallic copper [7].

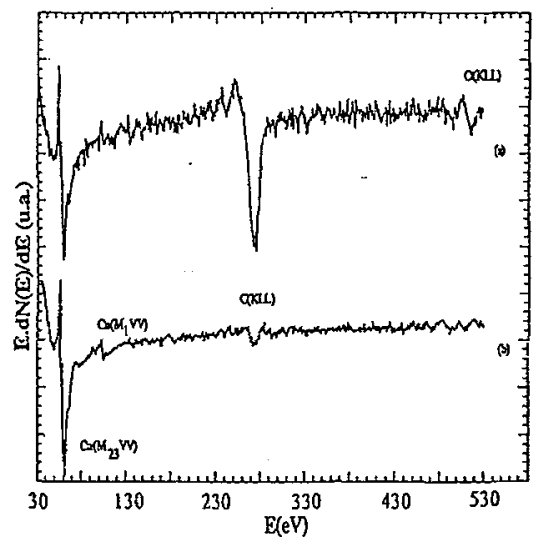

Figure 2: $\quad$ Auger spectrum of a typical film (a) as processed, (b) after $\mathrm{Ar}^{+}$ion sputtering of the deposit surface. The experimental conditions were : total pressure $10^{-1}$ Torr, gas flow $1 \mathrm{sccm}$, ratio $\mathrm{O}_{2} / \mathrm{Cu}(\mathrm{acac})_{2}=1.5$ and substrate temperature $375^{\circ} \mathrm{C}$.

Figure 3 shows the comparative deposit morphology, obtained in different experimental conditions, observed by AFM. At a given copper layer thickness of $850 \AA$ (Figure $3 \mathrm{a}, \mathrm{b}, \mathrm{c}$ ), the film roughness and grain size increased with the substrate temperature. The root mean square roughness (Rms) of 10,14 and $19 \mathrm{~nm}$ have been found at temperatures of 275,300 and $350^{\circ} \mathrm{C}$ respectively. When the substrate temperature was kept constant, the roughness increased with the film thickness and Rms of 13,51 and $75 \mathrm{~nm}$ have been found for layer thicknesses of 55,115 and $145 \mathrm{~nm}$ respectively at a substrate temperature of $350^{\circ} \mathrm{C}$ (Figure 3d, e, f). Note that the Rms reaches half the value of the layer thickness for thick films. The same effects have already been observed by Pauleau et al. [3] by Scanning Electron Microscopy. No influence of UV illumination has been observed on the layer roughness.

The deposit thickness increases linearly with the processing time (Figure 4) and consequently the deposition rate is meaningful. Furthermore, no nucleation delay is observed with copper deposition process within typical exposure durations investigated (15-300 minutes). The variation of the deposition rate with the copper acetylacetonate partial pressure has been studied at a substrate temperature of $325^{\circ} \mathrm{C}$ and a constant ratio $\mathrm{O}_{2} / \mathrm{Cu}(\mathrm{acac})_{2}$ equal to 1.5 (Figure 5). The deposition rate increases linearly with the precursor partial pressure and a slope of $625 \AA . \mathrm{min}^{-1}$. Torr ${ }^{-1}\left(10.4 \AA . \mathrm{s}^{-1}\right.$. Torr $\left.{ }^{-1}\right)$ has been found.

Figure 6 shows the dependence of the deposition rate with the substrate temperature under photoassistance or not at a gas flow of $1 \mathrm{sccm}$, a total pressure of $10^{-1}$ Torr and a concentration ratio of 1.5. In the range of $225^{\circ} \mathrm{C}$ to $300^{\circ} \mathrm{C}$ the reaction is thermally activated and the activation energies of $19 \mathrm{kcal} / \mathrm{mole}$ and $27 \mathrm{kcal} /$ mole have been respectively found for photoassisted or not photoassisted reactions. At substrates temperatures higher than $300^{\circ} \mathrm{C}$, the deposition rate was found to be independent of the temperature. At a given temperature, the growth rate was always enhanced by photoassistance and the deposition rate increase was about equal to $50 \%$ independently of the substrate temperature at a fixed concentration ratio $\mathrm{O}_{2} / \mathrm{Cu}(\mathrm{acac})_{2}$ chosen in the range of 1.5-2. When the concentration ratio was chosen higher than 2 , the reaction rate began to decrease when the oxygen concentration increased on the illuminated sample, till it stopped due to formation of copper oxide.

\section{DISCUSSION}

The two classical regimes in CVD processes (chemical regime and mass transport limited regime) are clearly observed on the Arrhenius plot (figure 6). At low temperatures $\left(225-300^{\circ} \mathrm{C}\right.$ ) the reaction is thermally activated and the activation energy of about 19 and $27 \mathrm{kcal} / \mathrm{mole}$ have been found respectively 
a)

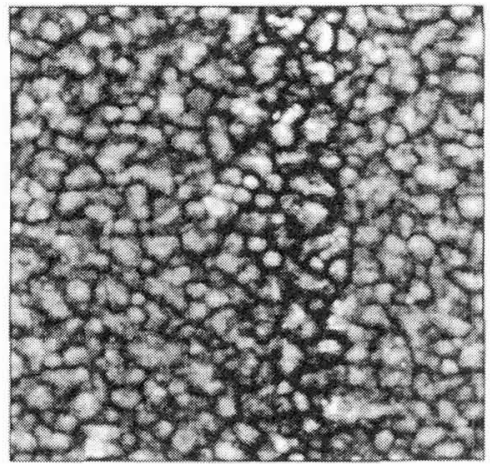

b)

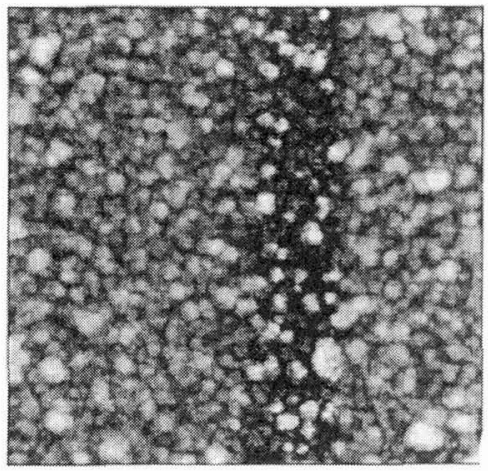

c)

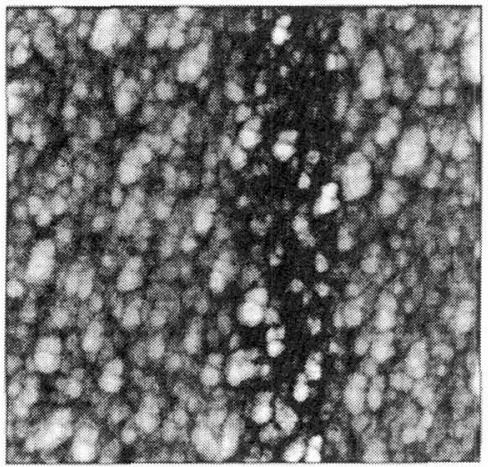

d)

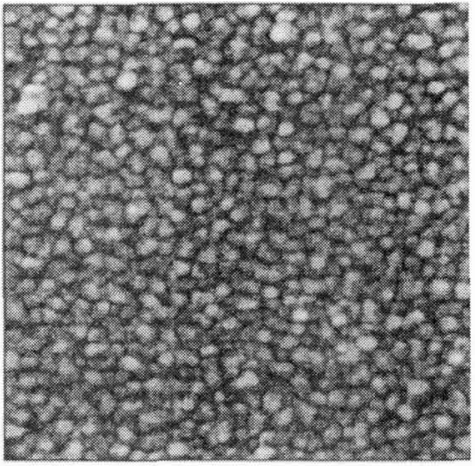

e)

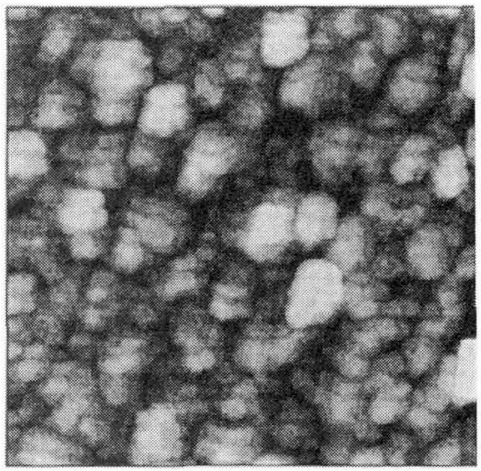

f)

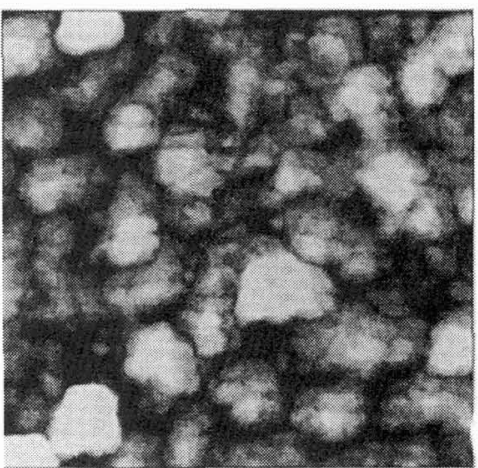

Figure 3: Morphology of the deposit observed by AFM as a function of substrate temperature and processing time. The experimental conditions are : total pressure $10^{-}$Torr, gas flow $1 \mathrm{sccm}$, ratio $\mathrm{O}_{2} / \mathrm{Cu}(\mathrm{acac})_{2}=1.5$. (a) $\mathrm{T}=350^{\circ} \mathrm{C}$, layer thickness $850 \mathrm{~A}$, (b) $\mathrm{T}=300^{\circ} \mathrm{C}$ layer thickness $800 \mathrm{~A}$, (c) $\mathrm{T}=275^{\circ} \mathrm{C}$, layer thickness 800 $\mathrm{A}$, (d) $\mathrm{T}=350^{\circ} \mathrm{C}$, layer thickness $550 \mathrm{~A}$ (e) $\mathrm{T}=350^{\circ} \mathrm{C}$, layer thickness $1150 \mathrm{~A}$, (f) $\mathrm{T}=350$, layer thickness 1450 A. Surface : $5 \times 5 \mu \mathrm{m}$. 
for photoassisted reactions and non photoassisted reactions. The activation energy of the reaction is lower with UV photoassitance which could indicate that the $\mathrm{Cu}$-ligand bonds of the precursor molecule are weakened under UV illumination. At temperatures higher than $300^{\circ} \mathrm{C}$, the deposition rate is independent of the substrate temperature, which is characteristic of a reaction limited by mass transport of oxygen or copper precursor. If UV photons were absorbed in the adsorbed layer (either by oxygen or precursor molecules), the deposition rate in the mass transport regime would be the same with and without photoassistance and the effect of photons would be observed only in the chemical regime. Since the deposition rate enhancement due photons is also observed in the mass transport regime, consequently, the UV photons are probably absorbed in the gaseous phase and not in the adsorbed layer, and enhance the adsorption of a reactive species.

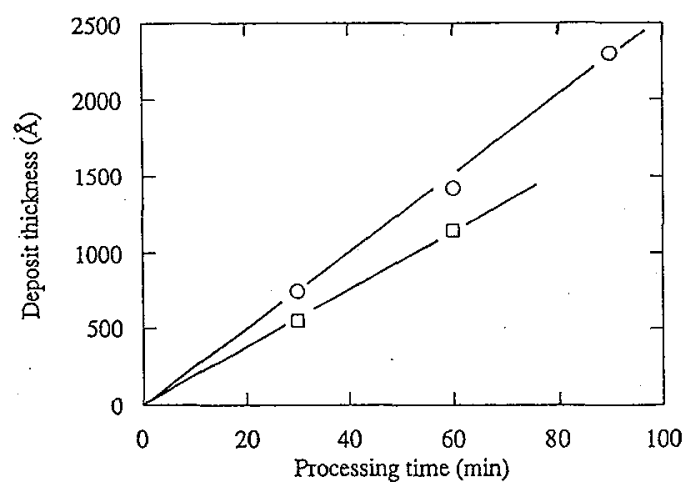

Figure 4: Dependence of the copper film thickness on the processing time. The experimental conditions were : total pressure $10^{-1}$ Torr, gas flow $1 \mathrm{sccm}$, ratio $\mathrm{O}_{2} / \mathrm{Cu}(\mathrm{acac})_{2}=1.5$ and substrate temperature $350^{\circ} \mathrm{C}$. (O) under UV illumination, $(\square)$ without photoassistance

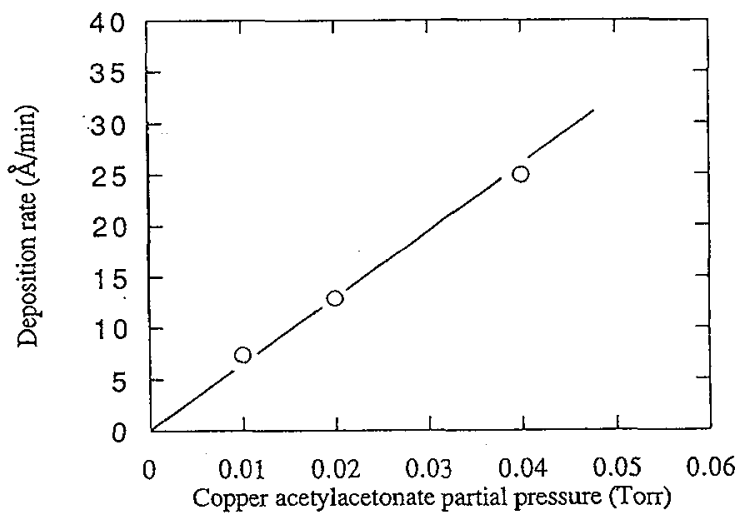

Figure 5: Dependence of the deposition rate on the $\mathrm{Cu}(\mathrm{acac})_{2}$ partial pressure. The substrate temperature was $350^{\circ} \mathrm{C}$, the gas flow $1 \mathrm{sccm}$ and the ratio $\mathrm{O}_{2} / \mathrm{Cu}(\mathrm{acac})_{2}$ was 1.5 .

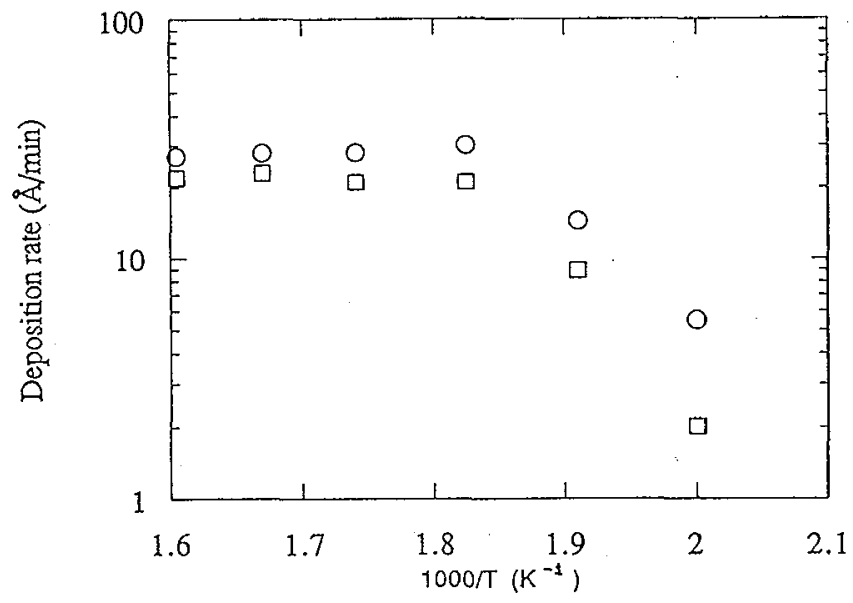

Figure 6: Dependence of the deposition rate on the substrate temperature. The total pressure was $10^{-1}$ Torr, the gas flow $1 \mathrm{sccm}$ and the ratio $\mathrm{O}_{2} / \mathrm{Cu}(\mathrm{acac})_{2}$ was 1.5. (O) under $\mathrm{UV}$ illumination, $(\square)$ without photoassistance. 
Furthermore, the deposition rate increases with the oxygen partial pressure at a given $\mathrm{Cu}(\mathrm{acac})_{2}$ pressure, untill the concentration ratio reaches the value of 2 in the case of photoassisted reaction (respectively 2.5 when the substrate is not illuminated). If the concentration ratio exceeds these values, the reaction stops and it is no more possible to deposit copper film. Since at a given precursor pressure the deposition rate increases with oxygen partial pressure and since the maximum threshold for oxygen partial pressure is lower in the case of photoassisted reaction, consequently the UV photoassistance probably enhances atomic oxygen adsorption, and at higher oxygen vapor pressure, all adsorption sites are occupied by oxygen atoms, which inhibits the chemical reaction.

In the mass transport regime, the maximum deposition rate of $10.4 \AA . s^{-1}$. Torr ${ }^{-1}$ has been found. This deposition rate has to be compared to the maximum growth rate of $26 \AA \mathrm{As}^{-1}$. Torr $\mathrm{r}^{-1}$ obtained by decomposition of $\mathrm{Cu}(\mathrm{hfac})_{2}$ at a precursor partial pressure of 0.4 Torr diluted in hydrogen at a total pressure of 10 Torr [8]. Consequently in both cases the sticking coefficients of the molecules are of the same order of magnitude.

The maximum deposition rate is very weak compared to the theoretical maximum deposition rate given by the kinetics theory of gases. In fact the maximum growth rate of $1500 \AA . \mathrm{s}^{-1} \cdot$ Torr $^{-1}$ has been calculated, assuming that the sticking coefficient of the $\mathrm{Cu}(\mathrm{acac})_{2}$ molecule is 1 and taking into account the diffusion coefficient of the precursor through oxygen and $\mathrm{Cu}(\mathrm{acac})_{2}$ molecules. Consequently the sticking probability of the $\mathrm{Cu}(\mathrm{acac})_{2}$ molecule on copper would be about $1 \%$. It has already been observed by Thermal Desorption Spectroscopy (TDS), that the initial sticking probability during the copper evaporation process on $\mathrm{SiO}_{2}$ substrates is unusually low (less than $10 \%$ at a temperature of $400^{\circ} \mathrm{C}$ ) but increases and reaches unity on metallic surfaces.

It is known that copper bishexafluoroacetylacetonate, $\mathrm{Cu}(\mathrm{hfac})_{2}$, adsorbs dissociatively on metallic surfaces and intact ligand wings (hfac) are observed on the substrate surface [4]. Desorption of this hfac radical after reprotonation is usually considered as the rate limiting step of the reaction of $\mathrm{Cu}(\mathrm{hfac})_{2}$ decomposition when the precursor is diluted with hydrogen [8].

However in the present case an analogous by-product molecule cannot be invoked in the oxidation of $\mathrm{Cu}(\mathrm{acac})_{2}$ since the molecule equivalent to the reprotonized acac radical obtained by hydrogen substitution by oxygen does not exist. Consequently, in presence of oxygen, the acac radical is probably not stable and dissociates itself providing other radicals, which occupy the adsorption sites and impede adsorption of new precursor molecule. This could explain the very low sticking probability of the $\mathrm{Cu}(\mathrm{acac})_{2}$ molecule on copper surfaces.

\section{CONCLUSION}

Copper deposition from dissociation of $\mathrm{Cu}(\mathrm{acac})_{2}$ precursor is possible in oxidizing atmospher. The reaction occurs at a temperature threshold of $275^{\circ} \mathrm{C}$. Under UV photoassistance this temperature threshold decreases down to $225^{\circ} \mathrm{C}$. This process leads to the formation of very pure deposits as observed by AES and $\mathrm{C}$ and $\mathrm{O}$ contamination is only observed at the deposit surface. The layer roughness was found to increase with the substrate temperature and film thickness.

The deposition kinetics have been studied and in the mass transport regime, the maximum growth rate of $10.4 \AA . s^{-1}$.Torr ${ }^{-1}$ has been obtained at substrate temperature of $350^{\circ} \mathrm{C}$ for $\mathrm{UV}$ photoassisted reactions. The sticking coefficient of the $\mathrm{Cu}(\mathrm{acac})_{2}$ molecule is $1 \%$. At a given temperature, the deposition rate can be increased of about $50 \%$ by UV photoassistance. At temperatures lower than $300^{\circ} \mathrm{C}$, the reaction is thermally activated with an activation energy of $27 \mathrm{kcal} / \mathrm{mole}$. Under UV photoassistance the activation energy of $19 \mathrm{kcal} / \mathrm{mole}$ has been found.

\section{References.}

[1]. A. E. Kaloyeros, M.A. Fury, MRS Bulletin, June 1993, Vol. XVIII, N6, 22-29.

[2]. Do-Heyoug Kim, R.H. Wentorf, W.N. Gill, J. Electrochem. Soc., 140(11), 3273-3279 (1993).

[3]. Y. Pauleau, A.Y. Fasasi, Chem. Mat. 1991, 3, 45-50.

[4]. S.L. Cohen, M. Liehr, S. Kasi, Appl. Phys. Lett. 60(13), 1585-1587 (1992). 
[5]. H. Dallaporta, Z. Hammadi, R. Pierrisnard, A. Cros, Proceedings of the 8th European Conference on CVD, ed. by M.L. Hitchman and N.J. Archer, Journal de Physique II, Vol.1, 889-895 (1991).

[6]. Z. Hammadi, H. Dallaporta, J. App. Phys., 73(10), 5213-5215 (1993).

[7]. Z. Hammadi, B. Lecohier, A. Cros, H. Dallaporta, Proceedings of the 9th European Conference on CVD, ed. by T. Mäntilä, Journal de Physique, Vol.3, 273-280 (1993).

[8]. Do-Heyoung Kim, R.H. Wentorf, W.N. Gill, J. of Electrochem. Soc., 140(11), 3267-3272 (1993).

[9]. Xueping Xu, D. W. Goodman, Appl. Phys. Lett. 61(15), 1799-1801 (1992). 